can scarcely be taken as being related to the group of spots that crossed the central meridian on Jan. 19.9. There were, however, several smaller groups following in longitude from which the solar disturbance, presumably responsible, might have originated.

\section{The Quadrantids, 1936}

MR. G. E. D. Alcock, of Peterborough, observed this shower on the early morning of January 4. The sky cleared at January 3, 13h. 45m. (G.M.A.T.) and clouded over at $15 \mathrm{~h} .55 \mathrm{~m}$. The moonlight was a big hindrance, but 17 meteors were mapped. Two radiants of Quadrantids were determined: $(a)$ $229 \frac{2}{3}^{\circ}+53^{\circ}$; diameter $1 \cdot 1^{\circ} ; 5$ meteors; (b) $229 \frac{1}{2}^{\circ}+49^{\circ}$; diameter $1 \cdot 4^{\circ} ; 6$ meteors.

\section{Announcements}

Sir Arthur Smith Woodward has been elected a member in the Section of Zoology, and Dr. Ulrich Wilcken (Berlin) a member in the Section of Historical and Philological Sciences, of the Royal Swedish Academy of Sciences.

The Council of the Institution of Naval Architects has awarded the premium of the Institution for the year 1935 to Mr. J. L. Scott, of Armstrong College (University of Durham), for his paper "A Simplified Form of Direct Flooding Calculations", and the Wakeham prize for the year 1935 to Mr. W. H. C. Nicholas, of Hull, for his paper "The Evolution of the Modern Steam Trawler with Superheating".

Dr. Fritz Lejeune, professor of the history of medicine at Cologne, has been elected a member of the Lisbon Academy of Sciences.

THE sixth International Congress of Physical Medicine will be held in London on May 12-16 under the presidency of Lord Horder. Further information can be obtained from the Honorary Secretary, Dr. Albert Eidinow, 4 Upper Wimpole Street, W.1.

THE opening meeting of the Photometric Section of the Illuminating Engineering Society, which was to have taken place on January 28, will take place at the Westminster Technical Institution, Vincent Square, S.W.I, at 7.0 p.m. on February 4, when Dr. J. W. T. Walsh will deliver his opening address.

We have received from Messrs. Charles Baker, 244 High Holborn, London, W.C.1, a copy of their latest catalogue of microscopes and accessories, which has just been published. Several new pieces of apparatus have been introduced since the publication of the last issue ; these include a Greenough binocular dissecting microscope, a low-voltage research microscope lamp, a school micro-projection outfit of moderate price, and a low-priced detachable universal mechanical stage for the microscope.

IN order to meet a demand for a vitamin preparation for medical practice, and particularly for hospital out-patients, British Drug Houses, Ltd., Graham Street, City Road, London, N.1, have introduced "Multivite Pellets". The preparation consists of chocolate-coated tablets, each tablet or 'pellet' containing vitamins A (3,000 international units), C (100 I.U.), and D (600 I.U.), together with vitamin $\mathrm{B}$ complex equivalent to $2 \mathrm{gm}$. of yeast. The dosage is, for adults 2-4, for children 1-2, pellets daily, which may be swallowed or eaten as a sweetmeat. Literature and sample will be forwarded on application.

THE spring programme of the Electrical Association for Women has recently been issued. The London branch has arranged an interesting series of lectures, papers and visits. Special lectures and demonstrations for teacher members have also been arranged in connexion with a Teachers' Circle which is open to members of the Association who are in the teaching profession. A special programme for a Demonstrators' Circle has also been arranged. The eleventh Annual Conference of the Association will be held at Park Lane Hotel, London, W.1, on March 13-15. Further particulars can be obtained from the Secretary of the Association, 20 Regent Street, London, S.W.l.

Dr. C. E. K. Mees, vice-president in charge of research and development at the Eastman Kodak Co., who has just delivered a course of Christmas lectures on "Photography" at the Royal Institution, is to embody the substance of them in a book which will be published in the autumn by Messrs. G. Bell and Sons, Ltd. Among the topics with which Dr. Mees will deal are the methods used in the manufacture of photographic films ; colour photography; the making of motion pictures, cartoons and sound recording; the application of photography in many fields of science and industry ; and the photography of coloured objects in black and white.

Erratum.--In a paragraph entitled "Transpiration and Stomata in Desert Plants" in NATURE of December 21, 1935 (p. 993), the authors of the paper under notice are wrongly given as A. H. Nontasir and A. M. Nigaleid; the authors are A. H. Montasir and A. H. Migahid.

Applications are invited for the following appointments, on or before the dates mentioned :

A lecturer in geography (woman) in Whitelands College, Putney, London, S.W.15-The Secretary (Feb. 14).

An official fellow in chemistry in Queen's College, Oxford-The Provost (Feb. 15).

Professors of economics, politics, pure chemistry and applied chemistry in Andhra University, Waltair, India-The Secretary, The Universities Bureau, 88a, Gower Street, London, W.C.1 (March 1).

A professor of physics in the University of Birming. ham-The Secretary (March 2).

A head of the Department of Mechanical and Structural Engineering and Building of the Borough Polytechnic, Borough Road, London, S.E.I-The Prineipal. 